\title{
PERANAN MAJLIS AMANAH RAKYAT DALAM PENUBUHAN DAN PERKEMBANGAN INSTITUT TEKNOLOGI MARA, 1966-1976
}

\author{
Zarina Begam binti Abdul Kadir \\ Ahmad Kamal Ariffin bin Mohd Rus
}

\begin{abstract}
This article attempts to analyse the role of Majlis Amanah Rakyat (MARA) in the development of Institut Teknologi Mara (ITM), within its 10 years of establishment. The basis of MARA's role was primarily initiated by the Malay scholars and politicians, due to their concern on Malay socio economic disparity after Independence. Hence, by the consensus of the Bumiputera Economics Congress in 1965, MARA has been established as the outcome of the restructuring of RIDA. In addition, through the MARA's initiative, Dewan Latihan RIDA has been upgraded to ITM in 1967. Also, by its further efforts, the Bumiputera's level of education has been improved and enhanced its economic values. Further, the introduction of the professional courses in that institution, has aimed for the sustainability of the ITM's graduates to compete in the higher income earnings market. Within 10 years of its establishment, it has shown a remarkable progress. However, due to the ineffectiveness administration of the Students' Affair to curb the 1976 students' riot, the ITM administration has been transferred to the Ministry of Education of Malaysia.
\end{abstract}

\section{Pengenalan}

Dekad terawal selepas kemerdekaan negara merupakan suatu tempoh yang sangat kritikal bagi kemajuan pendidikan orang Melayu. Bahasa Melayu umpamanya, meskipun telah diperundangkan sebagai bahasa 
pengantar di sekolah, namun disebabkan Bahasa Inggeris kekal menjadi bahasa pendidikan yang mempunyai nilai ekonomi, kemajuan Bahasa Melayu sebagai bahasa pengantar utama dalam sistem pendidikan negara dilihat sukar dilaksanakan.

Perkembangan sedemikian meresahkan para pemimpin dan cendekiawan Melayu. Mereka berpandangan hala tuju tersebut akan menatijahkan ketidakseimbangan lantaran memencilkan orang Melayu daripada arus kemajuan yang sewajarnya mereka kecapi. Bagi kumpulan ini, kerajaan perlu mengambil langkah afirmatif bagi memastikan penduduk majoriti dinegara ini mendapat hak yang setara. Mekanisme terbaik untuk merealisasikan harapan tersebut adalah menerusi kemajuan pendidikan. Namun apa yang menarik, mekanisme tersebut tidak digerakkan melalui Kementerian Pelajaran tetapi telah diputuskan untuk dikendalikan oleh satu institusi khusus, Majlis Amanah Rakyat; suatu badan di bawah portfolio Kementerian Luar Bandar.

\section{Penubuhan MARA}

Majlis Amanah Rakyat atau singkatannya MARA ditubuhkan pada 1 Mac 1966. ${ }^{1}$ Ia merupakan penjenamaan semula daripada RIDA dengan menampilkan struktur yang baru. ${ }^{2}$ Penubuhan MARA merupakan salah satu usaha untuk mengubah struktur kehidupan orang Melayu kepada kehidupan yang jauh lebih baik. Oleh sebab RIDA terlalu banyak kelemahan dan tidak begitu efisien dalam mengubah struktur kehidupan orang Melayu, maka cendekiawan dan ahli politik Melayu telah mendesak agar RIDA diberi nafas, semangat dan jiwa baru bagi membangunkan orang Melayu dalam dunia perniagaan, perindustrian dan pendidikan moden. Justeru itu, para cendekiawan dan ahli politik Melayu telah mengadakan satu kongres untuk membincangkan kedudukan orang Melayu dalam negara yang baru merdeka.

Kongres Ekonomi Bumiputera yang pertama telah berlangsung dari 5-7 Jun 1965 yang bertempat di Dewan Tuanku Abdul Rahman, Jalan Ampang, Kuala Lumpur. Sebuah jawatankuasa telah dibentuk bagi menganjurkan kongres ini. ${ }^{3}$ Tujuh lagi Jawatankuasa Kecil telah dibentuk yang membincangkan isu-isu yang berlainan. ${ }^{4}$ Kongres yang bersidang selama tiga hari ini bertujuan mengumpul pandangan daripada pelbagai pihak mengenai penyertaan Bumiputera dalam perdagangan dan perusahaan. Isu-isu yang menjadi asas perbincangan dalam Kongres tersebut mencakupi soal latihan, pembentukan modal ${ }^{5}$, perkhidmatan ${ }^{6}$, perdagangan ${ }^{7}$, perusahaan, tanah dan juga pemasaran ${ }^{8}$. Antara perkara utama yang dibincangkan ialah dari aspek latihan dan pendidikan. Kongres bersetuju untuk memberikan pendedahan 
yang lebih meluas dalam aspek pendidikan agar dapat melahirkan bumiputera yang mampu menjawat jawatan yang tinggi.

Selain itu, usul berkaitan latihan dan pendidikan ini juga adalah untuk melahirkan anak-anak bumiputera yang bertauliah serta layak menyertai bidang-bidang profesional. Resolusi yang diputuskan dalam kongres ini telah diserahkan kepada kerajaan untuk dikuatkuasakan. Langkah pertama yang dilakukan oleh kerajaan ialah dengan menubuhkan Bank Bumiputera, Lembaga Pasaran Pertanian Persekutuan atau Federal Agricultural Marketing Authority (F.A.M.A), Syarikat Kebangsaan Bumiputera dan menubuhkan Majlis Amanah Rakyat (MARA). Dengan penubuhan MARA ini bererti segala tugas dan dasar yang dijalankan oleh RIDA sebelum ini akan ditamatkan sama sekali.

MARA merupakan sebuah badan baru dan mempunyai bentuk pentadbiran yang baru. Ini bermakna dengan lulusnya rang undangundang penubuhan MARA, segala perkara berkaitan RIDA tidak akan digunapakai lagi. Oleh sebab terdapatnya tuntutan penubuhan MARA menggantikan RIDA, maka kerajaan telah mengambil tindakan segera dan pada bulan Disember 1965, Parlimen Malaysia telah meluluskan Akta Majlis Amanah Rakyat atau MARA dan pada 1 Mac 1966, MARA telah ditubuhkan. ${ }^{9}$ Penubuhan MARA ini telah dinyatakan seperti berikut:

Adalah dengan ini ditubuhkan suatu badan berkanun dengan nama Majlis Amanah Rakyat (dalam Akta disebut sebagai Majlis) yang berkekalan turun temurun dan mempunyai suatu meteri dan boleh mendakwa dan didakwa atas namanya dan, tertakluk kepada dan bagi maksud-maksud Akta ini, boleh membuat kontrak-kontrak dan boleh memperolehi, membeli, mengambil, memegang dan menggunakan harta alih dan yang tidak alih bagi segala jenis dan boleh memindah, menyerahkan, melepas, menyerah, menggadai, menggadaijanji, memberi sewa, menyerahkan hak semula, memindahmilik atau dengan jalan lain melepaskan, atau membuat apa-apa berkenaan dengan, apa-apa harta alih atau tidak alih atau apa-apa kepentingan dengannya yang menjadi kepunyaan Majlis mengikut syarat-syarat yang difikirkan patut. ${ }^{10}$

Pada masa Tun Hj Abdul Razak membentangkan rang undang-undang MARA di Dewan Rakyat, beliau menjelaskan mengenai penubuhan MARA seperti berikut:

Tujuan cita-cita untuk menubuhkan satu perbadanan (MARA) ialah supaya ada sebuah lembaga yang boleh menjalankan dasar kerajaan untuk membaiki iktisad di luar bandar dan memberi mereka itu peluang lebih besar dan lebih luas lagi dalam lapangan perniagaan 
dan perusahaan. Sehingga hari ini, tugas itu dijalankan oleh RIDA, akan tetapi RIDA ditubuhkan pada masa penjajahan dulu dan tidak mempunyai bentuk, nafas dan jiwa yang boleh menjalankan tugas yang penting ini sesuai dengan kehendak rakyat di negara kita yang merdeka dan berdaulat ini. Dengan sebab itu difikirkan patutlah RIDA ini digantikan dengan Lembaga baru yang mempunyai bentuk, nafas dan jiwa yang baru. ${ }^{11}$

Di bawah susunan yang baru ini, MARA seperti juga RIDA diletakkan di bawah Kementerian Pembangunan Negara dan Luar Bandar. Ia terdiri daripada seorang pengerusi berserta empat belas orang ahli. Ahli-ahli Majlis ini adalah wakil dari Kementerian Kewangan, seorang dari Kementerian Perdagangan dan Perusahaan, seorang dari Kementerian Pertanian dan Syarikat Kerjasama, dua orang ahli dari Kementerian Pembangunan Negara dan Luar Bandar, lima orang ahli yang berpengalaman dalam bidang perniagaan dan perusahaan dan empat orang ahli lain. Pengerusi Majlis merupakan Pengerusi MARA. Sebuah Jawatankuasa Kerja diwujudkan bagi memantau serta meluluskan projek-projek MARA.

Susunan pentadbiran MARA dibahagikan kepada tujuh bahagian dan diketuai oleh Pengarah Bahagian masing-masing. Setiap Pengarah ini akan bertanggungjawab sepenuhnya dalam melaksanakan arahan Pengerusi MARA. Mereka yang dipilih adalah terdiri daripada pegawai yang dikenalpasti mempunyai semangat yang tinggi, keikhlasan bekerja dan komited dalam tugas yang diberikan. Tujuh bahagian tersebut adalah terdiri daripada lima bahagian bergerak atau 'Operating Divisions' iaitu bahagian latihan, pinjaman, kenderaan, perusahaan dan perdagangan serta khidmat nasihat. Dua bahagian lain merupakan bahagian Perkhidmatan dan Kira-kira yang terletak di bawah kategori perkhidmatan. ${ }^{12}$ Carta 1 merujuk kepada carta organisasi MARA yang diwujudkan pada tahun 1966.

\section{Peranan MARA}

Tugas yang dipikul oleh MARA boleh dibahagikan kepada tiga bahagian. Pertama, sebagai ejen pemberi latihan kepada ahli perniagaan dan golongan Bumiputera yang mempunyai keinginan untuk menjalankan perniagaan. Mereka akan diberi latihan, pinjaman wang atau bantuan modal dan diberi bantuan serta nasihat sehingga seseorang peniaga itu dapat menjalankan perniagaan mereka dengan sebaiknya. Selain itu, Dewan Latihan RIDA juga akan diperluaskan lagi peranannya supaya dapat memberi latihan khususnya untuk pemuda dan pemudi yang berasal dari kampung. ${ }^{13}$ 


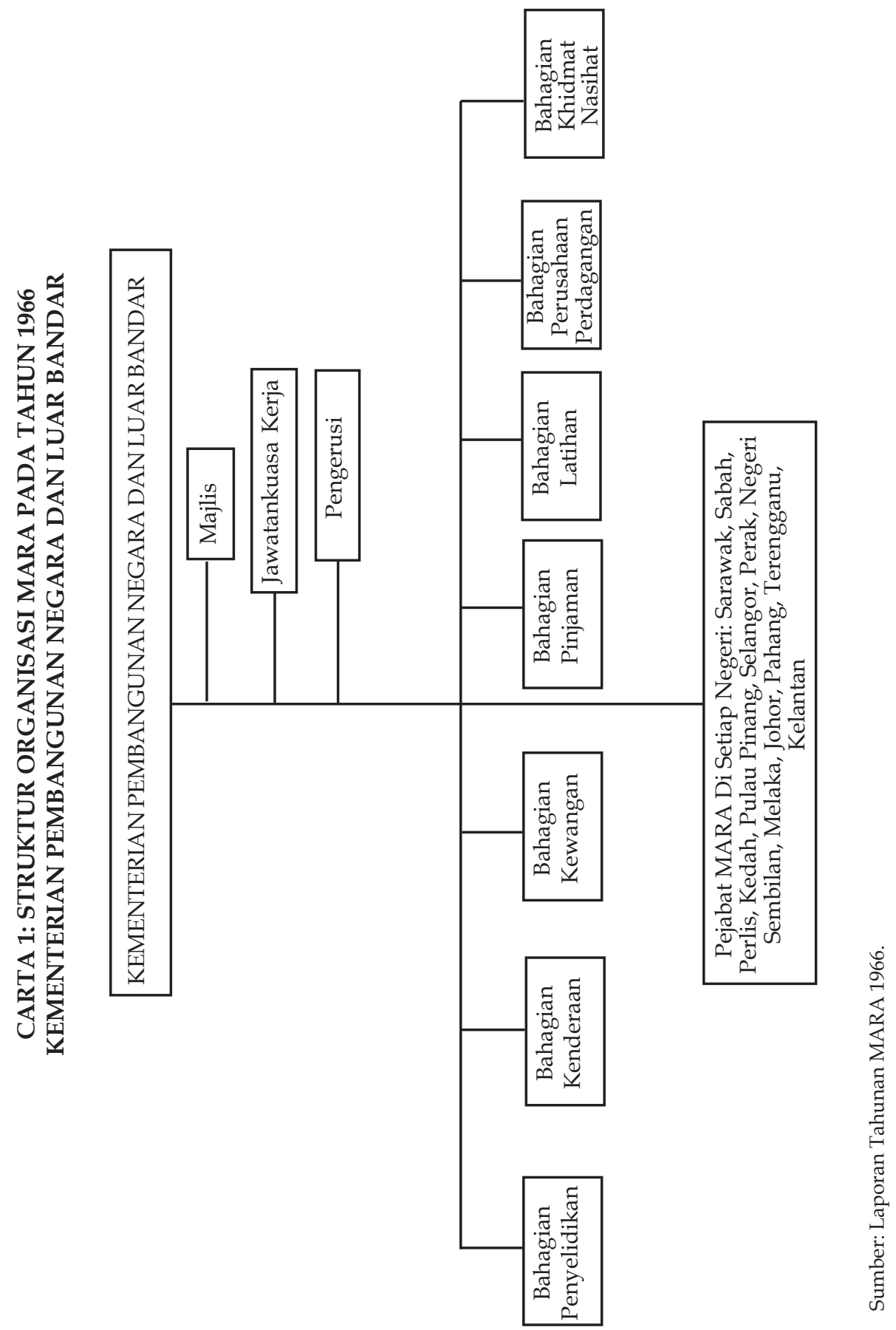


Tugas kedua ialah dalam lapangan pengangkutan yang mana MARA akan memberi pertolongan kepada syarikat bumiputera yang ingin menjalankan perkhidmatan bas dan teksi di kawasan luar bandar. MARA juga menyediakan peluang agar penduduk dapat membeli saham yang mereka kehendaki. Pelbagai langkah efisien diambil agar perkhidmatan bas yang disediakan tidak akan membawa kerugian kepada penduduk luar bandar pada masa akan datang. Manakala tugas ketiga ialah dalam lapangan perusahaan dan perdagangan yang mana MARA akan memainkan peranan dalam memberikan bantuan kepada penduduk luar bandar yang sedang menceburi bidang perusahaan. ${ }^{14}$

Oleh sebab bidang latihan merupakan fokus utama MARA, peruntukan sebanyak $\$ 400,000$ telah diberikan pada tahun 1966 khusus untuk melatih bumiputera dalam pelbagai jurusan pelajaran seperti stock exchange, pentadbiran kewangan, pengurusan hotel, perdagangan dan iklan, perusahaan getah, perusahaan kayu-kayan dan kilang papan, memperbaiki radio dan televisyen dan sebagainya. ${ }^{15}$ Bahagian Latihan dan Pendidikan merupakan antara bahagian yang penting dan dipertanggungjawabkan untuk meningkatkan mobiliti sosial masyarakat. Pada 1 Julai 1966, Encik Mansor telah dipinjamkan oleh Syarikat Shell kepada MARA bagi menjalankan tugas sebagai Pengarah. Oleh yang demikian, Encik Mansor bin Othman ${ }^{16}$ telah dilantik sebagai Pengarah Bahagian Latihan. Beliau telah memperkemaskan Bahagian Latihan MARA sehingga jumlah ahlinya menjadi tiga kali ganda dari sebelumnya. Beliau telah menyediakan anggaran dasar rancangan lima tahun Bahagian Latihan yang menelan belanja sebanyak \$81 juta. Beliau telah memikul tanggungjawab dalam mengubah sikap pegawai dan kakitangan MARA khususnya dan masyarakat luar bandar amnya. Selain itu, beliau merupakan seorang yang bertanggungjawab dalam mencetuskan idea bagi pengenalan sistem pendidikan menengah dan vokasional. Beliau merupakan seorang pemimpin yang berwibawa dan berwawasan dalam mencorakkan asas pendidikan di bawah MARA.

\section{Penubuhan Institut Teknologi MARA (ITM)}

Pada Februari hingga Mei 1965, kerajaan Malaysia bersama dengan United Nations telah mengadakan Kajian Sumber Manusia yang pertama. Hasil kajian tersebut mendapati bahawa berlaku lebihan graduan bagi bidang kemanusiaan dan undang-undang manakala berlaku kekurangan graduan di bidang sains dan kejuruteraan. Graduan yang mengisi kursus-kursus kemanusiaan ini majoritinya Bumiputera. ${ }^{17}$ Hasil kajian tersebut mendorong kerajaan mengadakan Kongres Ekonomi Bumiputera selama tiga hari bagi membincangkan peluang yang perlu diwujudkan untuk membantu bumiputera. Bidang yang 
difokuskan merangkumi bidang perdagangan dan perindustrian seperti yang dinyatakan oleh Kajian Sumber Manusia iaitu: "It is unfortunate, however that the Bumiputera do not have sufficient representation in the higher professional fields, particularly in business technological and scientific occupations, and in certain of the listed professions the Bumiputera can hardly be said to be represented at all."18

Aspirasi untuk membangunkan bangsa Melayu telah melahirkan Kongres Ekonomi Bumiputera yang bermatlamat untuk mencari jalan bagi mengatasi jurang ekonomi penduduk luar bandar dan meningkatkan taraf sosio-ekonomi mereka. Hasilnya sebanyak 69 usul telah disarankan dan sebanyak 22 usulnya melibatkan fungsi dan peranan RIDA. Antara usul penting ialah memberi nafas baru serta wajah baru kepada RIDA apabila namanya ditukarkan kepada Majlis Amanah Rakyat pada 1 Mac 1966 seiringan dengan kelulusan Akta MARA yang telah diluluskan di Parlimen pada Disember 1965. Sejajar itu, Dewan Latihan RIDA telah bertukar nama kepada Maktab MARA atau MARA College of Business and Professional Studies. ${ }^{19}$

Mesyuarat Kongres Ekonomi Bumiputera telah mencadangkan agar Maktab MARA dapat diperbesarkan lagi supaya ia boleh mengeluarkan pemuda-pemudi yang berkelulusan seramai 200 orang dalam tahun pertama dan juga dalam tahun kedua supaya angka tersebut dapat dilipat gandakan sepuluh kali lagi tiap-tiap tahun dari tahun ketiga dan seterusnya. Kongres juga mencadangkan agar kursus yang diadakan di bawah Maktab MARA diteruskan bagi melahirkan lebih ramai bumiputera yang bertauliah dalam bidang perniagaan dan perusahaan. ${ }^{20}$ Pada September 1965, Encik Arshad Ayub telah dilantik sebagai Pengetua Maktab MARA hingga tahun 1967. Beliau telah membuka peluang keemasan bagi anak bumiputera untuk meningkatkan diri mereka. Ada di antara pelajar itu kurang layak tetapi beliau memberi peluang bagi mereka belajar di maktab ini. Prinsip yang dipegang oleh beliau ialah "lead them to the water and ensure that they drink it". ${ }^{21}$

Maktab MARA telah berusaha mewujudkan kursus dalam Pengurusan Perniagaan. Ealing Technical College $e^{22}$ di London telah memberi kerjasama kepada Maktab MARA bagi membolehkan kursus Business Management diberi pengiktirafan yang sewajarnya. Ealing College bersetuju untuk menjadi pemeriksa luar bagi menjamin kualiti diploma di Maktab MARA. Dalam kepesatan permintaan untuk memasuki Maktab MARA, kerajaan telah mengambil langkah untuk memperbesarkan maktab tersebut. Suatu projek baru telah dirancang untuk diadakan di Batu Tiga, Jalan Klang Lama. ${ }^{23}$ Pada tanggal 14 Oktober 1967, batu asas untuk kompleks setinggi 15 tingkat di Shah Alam telah diletakkan oleh Tun Abdul Razak yang seterusnya 
mengumumkan penukaran nama Maktab MARA kepada Institut Teknologi MARA (ITM) atau MARA Institute of Technology (M.I.T). ${ }^{24}$ Penukaran nama kepada nama institut merupakan satu langkah menaiktaraf Maktab MARA agar peranannya dipandang lebih tinggi oleh masyarakat secara amnya. Lokasi baru maktab ini pada asalnya hanyalah merangkumi 100 ekar sahaja tetapi jumlah keluasannya telah ditambah sehingga 300 ekar . Pembinaan ini dijalankan di Batu Tiga, Shah Alam dengan menelan kos sebanyak \$6.75 juta dan dilengkapi oleh segala bentuk kemudahan pengajian. Pembinaannya bermula pada tahun 1968 dan dijangka siap pada tahun 1972. ${ }^{25}$

Matlamat penubuhan ITM ialah untuk mengadakan program pendidikan yang disesuaikan dengan keperluan tenaga manusia terutama dalam bidang teknologi, perniagaan, pengurusan dan pentadbiran. Ia juga bertujuan untuk menyediakan peluang pendidikan kepada belia-belia Bumiputera terutama bagi mereka yang datang dari kawasan luar bandar supaya mereka dapat mengambil bahagian yang penting serta memainkan peranan yang berkesan dalam sektor perdagangan dan perindustrian. Selain itu, ia juga bertujuan untuk memastikan agar lulusan ITM mendapat pekerjaan dan memegang jawatan dalam pelbagai bidang ekonomi negara serta diberi pengiktirafan yang sewajarnya. ITM juga berhasrat untuk memupuk sikap yang lebih positif dalam diri belia-belia Bumiputera agar mereka lebih bersedia dalam menghadapi persaingan dunia yang kian mencabar. Bagi merealisasikan impian ini, program-program pendidikan ITM akan dikaji dan dinilai supaya kaedah pembelajaran di ITM dan kurikulumnya tetap utuh dan sesuai mengikut kehendak semasa. Dengan ini, ITM dapat menyediakan sumber tenaga manusia dan material bagi memenuhi keperluan sektor-sektor awam, swasta dan masyarakat secara keseluruhannya. ${ }^{26}$

Objektif utama ITM bagi melahirkan seberapa ramai tenaga kerja Bumiputera dalam pelbagai bidang yang bertaraf profesional dan semi profesional dalam tempoh Rancangan Malaysia Ketiga semakin diperhebatkan. Selain itu, ITM juga bertujuan untuk memperbaiki dan mempertingkatkan lagi mutu pengajaran supaya dapat mengeluarkan graduan yang benar-benar bermutu tinggi dan setanding dengan graduan dari institusi pengajian tinggi yang lain. ${ }^{27}$ Objektif dan matlamat ITM ini adalah selaras dengan hasrat kerajaan yang mahu mengatasi kekurangan Bumiputera dalam bidang perdagangan, industri dan profesional. Bumiputera seharusnya menerima perubahan untuk membentuk masyarakat yang dinamik dan mampu berdaya saing. Melalui MARA diharapkan agar jurang pemisah antara Bumiputera dan bukan bumiputera dalam sektor ekonomi dapat dikurangkan. 
Seandainya masyarakat yang adil dan sama rata ini dapat dibentuk, ini akan menjadi kejayaan terbesar MARA. ${ }^{28}$

Sebanyak \$70 juta telah diperuntukkan kepada MARA dalam Rancangan Malaysia Pertama. Peruntukan ini digunakan oleh MARA bagi tujuan perkembangan pelajaran dan latihan. ${ }^{29}$ Dalam merealisasikan mandat kerajaan ini, perubahan perlu dilakukan untuk memperbetulkan kepincangan yang sering berlaku dalam organisasi ITM. Oleh sebab ITM merupakan satu institusi yang besar seperti institusi pengajian tinggi yang lain, maka didapati susunan pentadbiran ITM tidak sesuai lagi dengan peranan barunya sebagai institusi pengajian tinggi. Pentadbiran ITM di bawah kawalan Ibu Pejabat MARA meliputi pengawalan dari semua aspek terutama dari segi kewangan dan urusan kakitangan. Antaranya ialah peraturan tentang perbelanjaan daripada peruntukan belanjawan ITM adalah secara 'recoupment', akuan impress dan melalui kebenaran Pengarah Bahagian Latihan sebelum tiap-tiap perbelanjaan dapat dijalankan. Peraturan ini sesuai pada masa lepas iaitu ketika ITM itu masih lagi sebuah maktab yang kecil. ${ }^{30}$ Apabila ia berkembang pesat dan mempunyai bilangan pelajar dan kakitangan yang ramai, ia merumitkan dan menyukarkan pihak ITM dalam menyelesaikan tugas mereka.

Selain itu, kuasa yang diturunkan ke atas Pengarah ITM adalah amat sedikit iaitu mengawasi kakitangan dari segi inisiatif dan tatatertib sahaja. Ini berikutan sekatan-sekatan yang diletakkan ke atas kekuasaannya di bawah peraturan sekarang. Sungguhpun ITM bertanggungjawab atas kelicinan kerja dan kecekapan kakitangannya, ia tidak mempunyai kuasa yang berkesan untuk mengambil tindakan segera dalam mengendalikan tugas kakitangannya. Keperluan mengendalikan tugas-tugas ITM yang semakin berkembang serta menjamin kelicinan perbelanjaan kerajaan yang amat besar, maka perlulah diberi lebih autonomi kepada ITM untuk bertindak supaya institut ini benar-benar bertanggungjawab dalam segala urusannya. ${ }^{31}$

\section{Struktur Pentadbiran ITM}

Bahagian Kemajuan Pentadbiran Jabatan Perdana Menteri juga mencadangkan supaya sebuah Majlis Pentadbir (Governing Council) atau Lembaga Pentadbir ditubuhkan untuk mentadbir Institut ini dalam urusan harian. Majlis ini hendaklah bertanggungjawab terus kepada Pengerusi MARA. Untuk mencapai kelicinan dalam pentadbiran, maka dicadangkan kepada MARA agar menubuhkan suatu Lembaga Pengelola ITM (MIT Governing Council) yang mana Majlis akan menyerahkan segala kuasa (delegation) berkenaan dengan tanggungjawab ITM termasuk pentadbiran, kewangan, syarat-syarat bekerja dan sebagainya kepada Majlis tersebut. Selain itu, dicadangkan 
agar perubahan pentadbiran dan struktur organisasi ITM dilaksanakan. Ia juga mencadangkan agar ditubuhkan empat atau lebih buah Panel Penasihat (Advisory Panel) bagi Lembaga ITM berkenaan dengan penubuhan kursus-kursus baru untuk mengeratkan hubungan di antara badan-badan profesional dan memberi peluang bekerja kepada siswa-siswi ITM. ${ }^{32}$

Justeru, telah ditubuhkan sebuah Majlis Pentadbir. Majlis ini ditubuhkan pada 15 Januari 1970. Encik Ghaffar Baba selaku Pengerusi MARA telah mengumumkan penubuhan Majlis Pentadbir ITM bagi membantunya mentadbir institusi tersebut. ${ }^{33}$ Menurut beliau, majlis ini akan memberi nasihat mengenai pentadbiran, kewangan dan juga jenis kursus yang patut dikendalikan di institut ini. Majlis ini akan bertindak sebagai Badan Eksekutif institut dalam menjalankan segala aktiviti dan mengelola serta mengawal dan mentadbir institut ini. ${ }^{34}$ Majlis Pentadbir ini bukanlah satu badan berautonomi kerana ia masih terletak di bawah pengawalan Pengerusi MARA. Anggota Majlis ini terdiri daripada 18 orang iaitu dalam kalangan Pegawai Kanan Kerajaan dan wakil dari badan profesional dan pihak-pihak lain. ${ }^{35}$

Pengetua ITM iaitu Encik Arshad Ayub dilantik menjadi Setiausaha kepada Majlis Pentadbir tersebut. Keahlian majlis ini akan dilantik dua tahun sekali. Meskipun Majlis Pentadbir ini ditubuhkan namun soal kewangan termasuk peruntukan kewangan ITM masih dibuat oleh Ibu Pejabat MARA tetapi majlis berpeluang untuk mengemukakan syor-syornya. Dengan penubuhan Majlis Pentadbir bererti kuasa MARA terhadap ITM semakin longgar. MARA tidak mentadbir ITM secara langsung tetapi melalui Majlis yang lebih banyak menjalankan fungsinya. ${ }^{36}$

Keahlian Majlis Pentadbir ini juga menampakkan bahawa wakil dari pelbagai sektor kerajaan telah diambil dan bukan menjurus kepada kakitangan ITM sendiri ataupun MARA. Ini telah melahirkan perasaan kurang senang dalam kalangan Kesatuan Siswa Siswi ITM (KSITM). Kesatuan ini menyifatkan Majlis Pentadbir ITM sebagai satu pembolotan kuasa kerana komposisi majlis ini tidak dipilih secara bijak. Ini disebabkan wakil dari ITM seperti para pensyarah tidak dipilih sedangkan peranan mereka sangat penting dalam memperbaiki perjalanan ITM ke arah yang lebih cemerlang. ${ }^{37}$ Pendek kata, peralihan pucuk pentadbiran ini telah membawa ITM memasuki zaman baru dan masa depannya dikendalikan sepenuhnya oleh Majlis Pentadbir atau juga dikenali sebagai Majlis ITM. Pengerusi Majlis Pentadbir yang pertama ialah Tan Sri Ghazali bin Shafie. ${ }^{38}$ Beliau dibantu oleh Datuk Mansor bin Othman sebagai Naib Pengerusi. ${ }^{39}$ 


\section{Perkembangan Kursus Di ITM}

Perubahan pentadbiran juga telah membawa kepada perkembangan baru dalam kursus yang diambil oleh pelajar. Dalam tempoh 1964-1969, kebanyakan graduan adalah daripada kursus kesetiausahaan. Walau bagaimanapun, sejak 1970 bilangan graduan telah meningkat dan menjurus kepada bidang perniagaan, sains gunaan dan perakaunan. ${ }^{40}$ Selain itu, terdapat juga kursus baru seperti Mass Communication yang diperkenalkan bermula dari tahun 1972. Manakala kursus baru yang lain telah muncul hasil dari perkembangan kursus yang terdahulu. Antaranya ialah seperti Hotel and Catering Management pada tahun 1969.

Pada asalnya ia merupakan salah satu kursus di School of Library Science. School of Secretarial Science pada tahun 1974 ditubuhkan dari hasil pecahan School of Administration and Law. Manakala School of Art and Design muncul dari pecahan School of Art and Architecture. Di akhir tahun 1974, telah muncul lapan buah fakulti yang mengendalikan pelbagai program. Sebuah pusat bahasa telah ditubuhkan pada tahun 1972 manakala sebuah pusat pengajian jarak jauh ditubuhkan pada tahun 1973. ${ }^{41}$ Di bawah kepimpinan Encik Arshad Ayub, beliau telah mengelompokkan kursus-kursus ITM kepada lapan buah fakulti iaitu School of Accountancy, School of Administration And Law, School of Business and Management, School of Art and Architecture, School of Engineering, School of Pre-University Studies, School of Applied Science, School of Computer Science and Mathematics.

Kursus yang tersebut di atas ini telah diperkenalkan bagi memperluaskan lagi pilihan kursus yang sedia ada. Misalnya bagi kursus seperti Graphic Design, Textile Design dan Industrial Design merupakan kursus baru yang belum pernah diperkenalkan di Malaysia. Sebagai perintis, ITM menempuh kesukaran dalam memperoleh pengiktirafan bagi kursus tersebut. Malah, bagi kursus Computer Science, ITM menjadi institusi pertama yang menawarkan kursus tersebut. Kebanyakan kursus di peringkat awal adalah bertaraf Diploma dan merupakan kursus hasil kerjasama dengan universiti di luar negara. Ini merupakan salah satu strategi utama Pengarah ITM ketika itu iaitu Encik Arshad Ayub( kini Tan Sri) dalam memperkenalkan ITM dan meletakkan penanda aras yang tinggi sebagai kayu ukur pencapaian ITM. $^{42}$

Meskipun perkembangan sedemikian memperlihatkan suatu pencapaian yang memberangsangkan, namun bukanlah sesuatu yang mudah bagi MARA untuk merealisasikan segala pencapaian tersebut. MARA beruntung memiliki Encik Arshad Ayub sebagai Pengarah ITM ketika itu. Sebagai seorang pentadbir yang efisien, Arshad sering 
membuat keputusan sendiri dalam menerajui ITM. Beliau merasakan birokrasi kerajaan yang wujud akan melambatkan dan merencatkan pertumbuhan ITM. Beliau tidak gemar akan prosedur yang menyulitkan dalam membuat sesuatu keputusan. Ini secara tidak langsung membantu beliau dalam bertindak pantas merangka sesuatu dasar baru buat ITM. Bagi MARA pula, ITM bukan lagi satu bebanan kerana kemampuannya untuk bergerak sendiri tidak dapat dinafikan.

Misalnya, ketika Encik Arshad bertemu dengan Tun Abdul Razak (Perdana Menteri Malaysia ketika itu) bagi membincangkan perkembangan ITM, beliau mengambil kesempatan untuk mengemukakan masalah bajet yang tidak mencukupi untuk perkembangan ITM. Secara spontan, Tun Abdul Razak telah berhubung dengan Pengarah Unit Perancang Ekonomi iaitu Encik Tong Yaw Hong dan mengarahkan agar diberikan peruntukan sebanyak RM 9 juta untuk dibelanjakan selama tiga tahun lagi. Jelas di sini, beliau tidak melalui Majlis MARA untuk memohon peruntukan seperti yang selalunya dilakukan oleh pentadbir lain. Ia bukan bertujuan untuk membelakangkan pihak pentadbiran MARA tetapi hasrat beliau ingin mempercepatkan tugas yang tertangguh oleh sebab kekangan kewangan. Kepintaran beliau ini telah banyak membantu dalam perkembangan pesat ITM. ${ }^{43}$

\section{Perkembangan Pelajar}

Penambahan kursus yang baru juga membawa kepada peningkatan kemasukan pelajar, kemasukan pelajar pada Julai 1968 ialah seramai 2500 orang dan telah meningkat kepada 4,500 orang pada tahun 1972. Bukti yang ketara ialah pada era Encik Arshad Ayub selaku pengarah ITM yang mana ITM telah mengalami peningkatan pelajar dan pensyarah yang begitu mendadak. Perkembangan yang berlaku dapat dilihat melalui jadual di bawah:

Jadual 1: Jumlah Peningkatan Pelajar Dari Tahun 1965 Hingga 1974

\begin{tabular}{|c|c|c|}
\hline Tahun & Bilangan Pelajar & Pensyarah \\
\hline 1965 & 219 & 11 \\
\hline 1966 & 551 & 20 \\
\hline 1967 & 1491 & 82 \\
\hline 1968 & 2361 & 144 \\
\hline 1969 & 2542 & 184 \\
\hline 1970 & 2830 & 252 \\
\hline 1971 & 2641 & 309 \\
\hline 1972 & 3595 & 407 \\
\hline 1973 & 4775 & 589 \\
\hline 1974 & 6856 & 904 \\
\hline
\end{tabular}

Sumber: Centre for Strategic Planning UiTM 
Jadual di atas menunjukkan peningkatan jumlah pelajar dan kakitangan ITM yang begitu mendadak sekali. Bermula dengan seramai 219 orang pelajar dan 11 orang pensyarah pada tahun 1965, jumlah tersebut telah meningkat kepada 6856 orang pelajar dan 904 orang pensyarah pada tahun 1975. Ini bermakna, berlaku kenaikan sebanyak $96.8 \%$ bagi kategori pelajar manakala 98.7 peratus bagi kategori pensyarah. Jelas di sini menunjukkan program yang dijalankan oleh ITM mula mendapat tempat di hati masyarakat dan ia kian popular setanding dengan institusi pengajian tinggi yang lain. Ini bermakna ITM telah berjaya memecah minda masyarakat Melayu yang takut untuk menceburi kursus perdagangan dan perindustrian. Jumlah tenaga pengajar yang meningkat ini juga menunjukkan bahawa kepesatan dalam perkembangan kursus di ITM.

Jadual 2: Jumlah Graduan bagi Mengikut Kursus Bagi Tahun 1976

\begin{tabular}{|l|c|}
\hline Jenis Fakulti & Jumlah Graduan \\
\hline Kejuruteraan & 154 \\
\hline Pengurusan Hotel dan Penyediaan Makanan & 36 \\
\hline Pentadbiran dan Undang-undang & 71 \\
\hline Perniagaan dan Pengurusan & 192 \\
\hline Perakaunan & 109 \\
\hline Sains Gunaan & 209 \\
\hline Sains Kesetiausahaan & 93 \\
\hline Sains Hisab dan Komputer & 38 \\
\hline Sains Perpustakaan & 38 \\
\hline Sebaran Am & 32 \\
\hline Senibina, Perancangan dan Ukur & 94 \\
\hline Senilukis dan Senireka & 69 \\
\hline Jumlah & 1,135 \\
\hline
\end{tabular}

Sumber: Laporan Tahunan Institut Teknologi MARA 1976, hlm. 33-61.

Jadual 2 menunjukkan jumlah graduan bagi setiap fakulti bagi tahun 1976. Fakulti yang menghasilkan graduan paling tinggi ialah Sains Gunaan manakala paling rendah ialah Sebaran Am. Manakala jumlah keseluruhan graduan bagi tahun 1976 ialah sebanyak 1,135 orang graduan. Jumlah graduan yang dihasilkan oleh ITM ini adalah selaras dengan usaha kerajaan bagi membasmi kemiskinan dan menyusun semula masyarakat. ITM telah memainkan peranan penting sebagai salah sebuah pusat pengajian tinggi yang dinamis dalam melahirkan usahawan-usahawan dan eksekutif-eksekutif bumiputera yang terlatih melalui pelajaran dan latihan praktik. Di samping itu, ITM juga bakal menyediakan tenaga kerja yang amat dikehendaki oleh negara dalam perkembangan dan kegiatan ekonomi negara yang sangat pesat ini. Program yang dikendalikan oleh ITM adalah untuk melatih 
Bumiputera dalam bidang profesional dan semi profesional supaya dapat menyeimbangkan keperluan tenaga manusia di sektor-sektor swasta dengan kaum-kaum bukan Bumiputera.

Selain itu, ITM juga bertanggungjawab dalam melatih para graduan daripada aliran sastera supaya dapat menceburkan diri dalam bidang keusahawanan ataupun menjadi eksekutif dalam syarikat perniagaan dan perindustrian. Ia juga bertujuan untuk melatih peniaga Bumiputera yang baru meningkat naik supaya mereka menjadi ahli peniaga yang moden dan berpengalaman luas. Di samping itu, ITM juga ingin menyediakan konsep pelajaran ekonomi dengan lebih jelas kepada pelbagai peringkat pelajar dan guru.

\section{Peralihan Pengurusan ITM Ke Kementerian Pelajaran Malaysia}

Meskipun berlaku perkembangan yang pesat dari aspek akademik, namun rasa tidak puas hati sering muncul di hati pelajar terutama daripada aspek pentadbiran dan kedudukan ITM itu sendiri. Banyak pihak yang mula melahirkan hasrat agar ITM ini dinaikkan taraf ke tahap universiti. Misalnya Tan Sri Ghazali Shafie pernah melahirkan hasratnya agar ITM dijadikan pusat pengajian tinggi yang bebas. ${ }^{44}$ Bebas di sini bererti tidak berada di bawah naungan MARA. Selain itu, Setiausaha Parlimen Kementerian Pembangunan Negara dan Luar Bandar iaitu Haji Abu Bakar Hamzah juga telah melahirkan pendapat bahawa ITM sudah layak bergelar universiti. ${ }^{45}$ Akan tetapi cadangan ini tidak diendahkan oleh pihak kerajaan yang ketika itu begitu selesa meletakkan ITM di bawah MARA. Tuntutan mula dibuat oleh Kesatuan Siswa-Siswi Institut Teknologi MARA (KSITM) yang menuntut agar ITM dinaikkan ke taraf universiti. Ibrahim Ali selaku Presiden KSITM telah menggesa agar kerajaan memenuhi hasrat pelajar ITM ketika itu. ${ }^{46}$ Setelah diselidiki dan dikaji cadangan wakil pelajar, kerajaan telah mengambil keputusan untuk tidak membenarkan taraf ITM diubah. Ini disebabkan masih banyak perkara yang perlu diperbaiki dan kemudahan yang perlu dimajukan. Sekiranya ia dinaikkan taraf kepada taraf universiti, dikhuatiri ITM tidak mampu untuk bersaing dengan universiti lain pada ketika itu. ${ }^{47}$

Berikutan rasa tidak puas hati kerana suara mereka tidak dipenuhi, sebilangan pelajar ITM telah berjalan kaki dari kampus Shah Alam untuk berarak di hadapan bangunan Parlimen pada 22 April 1974. Mereka telah dileraikan oleh pasukan polis pada jam 5.30 pagi di Lebuhraya Persekutuan di simpang masuk ke Lapangan Terbang Subang serta berhampiran dengan Kampung Kerinchi. Pelajar-pelajar tersebut telah diarahkan untuk pulang semula ke kampus masing- 
masing bagi meneruskan pengajian. Berikutan tunjuk perasaan tersebut, Majlis Pentadbir telah mengambil keputusan untuk menutup ITM buat sementara waktu. ${ }^{48}$ Dua buah jawatankuasa telah dibentuk bagi mengkaji dan membuat laporan berkenaan dengan kejadian tersebut. Jawatankuasa yang pertama dipengerusikan oleh Encik Abdul Kadir Talib, Ketua Setiausaha Kementerian Pelajaran yang akan mengkaji berkenaan sebab-sebab dan kejadian yang membawa kepada tunjuk perasaan di dalam dan di luar kampus. Jawatankuasa yang kedua dipengerusikan oleh Encik Shev Charan Singh, seorang pegawai kanan dari Jabatan Peguam Negara yang mengkaji berkenaan dengan tindakan polis pada 22 April 1974 hingga 24 April 1974. Kedua-dua jawatankuasa ini dikehendaki menyiapkan laporan dalam tempoh tiga minggu. ${ }^{49}$

Tunjuk perasaan 1974 ini sedikit sebanyak menunjukkan rasa kurang senang dan protes yang wujud dalam kalangan pelajar. Pelbagai isu telah mula diperbesar-besarkan oleh pelajar dan dalam tahun 1975, Encik Arshad Ayub telah ditukarkan perkhidmatannya ke Bank Negara. Kementerian Pelajaran memikirkan perlunya seorang pengganti yang lebih bijak dalam arena pendidikan agar masalah pelajar yang semakin rumit ini dapat diatasi. Mereka mahukan seorang ahli akademik dan pentadbir yang berkebolehan. Calon yang dipilih ialah Datuk Haji Lokman bin Musa. Beliau pernah berkhidmat sebagai Pengarah Pelajaran Pahang, Pengarah Pelajaran Sabah, Pengarah Latihan GuruGuru Kementerian Pelajaran dan Pengarah Maktab Bahasa. ${ }^{50}$

Sebagai seorang yang telah lama berkecimpung dalam bidang akademik, Datuk Haji Lokman begitu menitikberatkan aspek disiplin dalam membentuk para pelajar. Langkah pertama yang beliau ambil ialah dengan menguatkuasakan peraturan disiplin yang sedia ada. Tindakan ini telah menimbulkan rasa kurang senang di hati pelajar yang selama ini sudah begitu asyik dengan gaya hidup bebas. Pelajar mula protes apabila mereka tidak berpuas hati terhadap tindakan pentadbir ITM yang telah mengumumkan peraturan yang akan diperketatkan di ITM di dalam akhbar. ${ }^{51}$ Tindakan ini diibaratkan telah memalukan para pelajar. Mereka marah kerana tidak diajak berunding terlebih dahulu. Pihak pentadbiran pula merasakan tidak ada apa yang perlu dirundingkan kerana semua peraturan tersebut telah termaktub dalam buku peraturan yang sedia ada, cuma tidak ada penguatkuasaan. Antara yang menimbulkan rasa tidak puas hati pelajar ialah soal berambut panjang yang disuarakan di dalam akhbar. ${ }^{52}$ Pada ketika itu, didapati ramai pelajar lelaki gemar menyimpan rambut panjang hingga sukar untuk membezakan antara lelaki dan perempuan.

Pelajar juga telah melemparkan beberapa tuduhan lain. Antaranya pihak pentadbir tidak berunding dengan mereka dalam hal-hal kewangan hingga berlakunya pembaziran. Sebagai contoh, pembinaan 
kolam renang di kampus yang dikatakan membazir sedangkan wang tersebut boleh disalurkan untuk perkara yang lebih penting. Selain itu, pelajar juga tidak berpuas hati dengan mesyuarat Majlis Pentadbir ${ }^{53}$ yang diadakan di Bukit Fraser untuk membincangkan tentang hal pentadbiran. Pelajar juga tidak berpuas hati dengan pelantikan Datuk Haji Lokman sebagai Pengarah ITM. Beliau merupakan seorang yang tegas dan berani dalam menguatkuasakan undang-undang. Akan tetapi beliau tidak digemari oleh pelajar dan sebarang tindakan beliau dianggap sebagai bapa yang ingin menjatuhkan keluarganya sendiri. Segala tindakan beliau telah disalahertikan dan dibandingkan dengan Bapa ITM iaitu panggilan untuk Encik Arshad Ayub (bekas Pengarah ITM) ${ }^{54}$ Meskipun pelajar menentang segala tindakan pentadbiran namun kuatkuasa undang-undang tetap dijalankan demi untuk menjamin kesejahteraan pelajar dan memastikan mereka dalam persekitaran akademik yang kondusif.

Berikutan rasa marah dan merasakan imej pelajar tercemar maka seramai 200 orang pelajar telah bertindak menghalang pendaftaran penuntut yang sepatutnya diadakan pada 5 Januari 1976. Mereka telah menghalang pensyarah daripada menjalankan pendaftaran. Mereka juga telah menggelarkan diri mereka sebagai golongan Gestapo. ${ }^{55}$ Kumpulan ini telah bermaharajalela dengan mengambil alih pentadbiran ITM. Malah, mereka telah mengugut para pelajar dengan menggunakan besi dan kayu agar menurut kata mereka. Antara ugutan mereka ialah menghalang pelajar keluar dari kampus. Mereka yang enggan menurut kehendak Gestapo ini akan dibogelkan dan dihiris dengan pisau ${ }^{56}$ Kumpulan ini baru muncul setelah timbul rasa tidak puas hati dalam kalangan pelajar. Meskipun pelbagai rundingan telah diadakan antara KSITM dan Pengarah ITM, namun wakil pelajar masih berdegil dan merasakan diri mereka tidak terbela.

Keadaan semakin meruncing apabila Dr Mahathir Mohamad yang ketika itu selaku Menteri Pelajaran telah mengesan aktiviti tidak sihat yang menular dalam kalangan pelajar ITM. Semasa pelajar bercuti, beliau telah mengambil kesempatan melawat sendiri ke asrama pelajar bagi melihat keadaan mereka. Hasil pemeriksaan beliau telah menjumpai beberapa senjata seperti tiga bilah kapak Siam, beberapa butir peluru, pedang samurai, pedang biasa, lawi ayam, beberapa bilah pisau dan kerambit. Di samping itu, beliau juga menjumpai alat menghisap dadah, gambar lucah, poster dan kad pengenalan tiruan. Ini membuktikan bahawa wujud budaya tidak sihat yang akan memberi kesan buruk kepada pelajar lain yang ingin belajar. ITM sebagai institusi pendidikan akan terjejas jika perkara sebegini tidak dibendung. ${ }^{57}$

Di pinggir jalan, kerajaan telah mengarahkan pasukan polis hutan untuk mengadakan sekatan jalan raya bagi tujuan keselamatan. Menurut 
tokoh politik ketika itu, antara punca berlakunya ketegangan ini ialah kerana masalah kurang komunikasi antara pentadbir dan para pelajar itu sendiri. Jurang komunikasi ini merupakan satu penyakit yang telah lama berakar umbi dalam kalangan pelajar. Hubungan renggang antara pihak pentadbiran dan pelajar telah memberi peluang kepada golongan aktivis untuk meracuni fikiran pelajar dengan bayangan-bayangan negatif. Mereka bertindak dengan menonjolkan permasalahan pelajar dan menimbulkan rasa tidak puas hati dalam diri pelajar. Mereka secara terang-terangan menyalahkan Pengarah ITM iaitu Datuk Haji Lokman Musa sebagai punca bagi segala masalah. Malah, pelajar telah menuntut agar beliau dilucutkan dari jawatannya dan diminta untuk memohon maaf kepada pelajar. ${ }^{58}$

Salah faham yang timbul dalam kalangan pelajar ini tidak dapat dileraikan. Malah pelbagai fitnah dan tohmahan telah dilemparkan kepada pihak pentadbiran. Majlis Pentadbir gagal untuk menyelesaikan kekusutan yang timbul. Keadaan ini telah mendesak Menteri Pelajaran untuk mengarahkan agar ITM ditutup serta-merta pada 8 Januari 1976. Penutupan ini adalah selama enam minggu dan semua pelajar telah diarahkan untuk keluar. Penutupan ITM ini bererti ibu bapa boleh membawa pulang anak-anak mereka sehingga keadaan kembali tenang. Ini bagi menjamin keselamatan pelajar, pensyarah dan harta benda ITM. Kira-kira 5000 orang pelajar berada di kolej ketika pengambilalihan kuasa tersebut. Sesiapa pun tidak dibenarkan masuk ke kampus termasuk pembekal yang menghantar makanan buat pelajar. Ibu bapa yang datang untuk mengambil anak mereka akan disoal terlebih dahulu dan perlu meninggalkan kad pengenalan mereka di bilik pengawal sebelum dibenarkan membawa pulang anak mereka. ${ }^{59}$

Meskipun arahan telah dikeluarkan, masih terdapat seramai 20 orang pelajar yang enggan dan bertindak bermaharajalela masuk ke bilik pejabat pentadbiran serta membakar surat-surat penting pada waktu malam. ${ }^{60}$ Tindakan segelintir pelajar yang tidak berminat terhadap pelajaran ini telah mengakibatkan pelajar yang lain turut menjadi mangsa. Timbul persoalan di sini, mengapakah pihak pentadbiran gagal untuk menangani salah faham yang wujud dalam kalangan pelajar? Kemampuan pihak pentadbiran ITM dicurigai kerana gagal menyelesaikan isu yang kecil ini. Adakah isu disiplin iaitu berambut panjang telah diperbesarkan hingga mencetuskan tunjuk perasaan? Adakah mungkin kegagalan ini timbul kerana ITM sendiri tidak mempunyai tenaga yang cukup untuk mengawal dan menjaga kesejahteraan para pelajar? Mungkin dari aspek akademik para pelajar telah diberi perhatian yang cukup tetapi bagaimana pula dari aspek kesejahteraan mereka di kampus? Dengan lain perkataan pihak pentadbiran mestilah mengambil berat terhadap masalah pelajar 
dan berada di sisi mereka bagi menyelesaikan masalah ini. Kegagalan pentadbiran ITM untuk menyelesaikan masalah ini juga adalah ekoran dari tiadanya kuatkuasa undang-undang untuk mengawal para pelajar. Sebelum ini, ITM tidak mengambil tindakan tegas terhadap para pelajar yang tidak berminat untuk belajar. Malah untuk menyingkirkan pelajar adalah amat sukar sekali. Kini, satu langkah baru telah diambil untuk menggubal satu Rang Undang-Undang Institut Teknologi MARA dan juga Akta Institusi Pelajar (1976) ${ }^{61}$

Rang Undang-undang ITM ini telah dibahaskan dan akhirnya diluluskan di Parlimen. Menurut Seksyen 3, ITM telah dijadikan sebagai sebuah badan berkanun dengan mempunyai kuasa yang biasanya diperuntukkan untuk sebuah badan berkanun. Ini bererti ITM tidak lagi duduk di bawah payung MARA seperti di awal penubuhannya. Malah ITM kini telah dipindahkan dari Kementerian Pembangunan Negara dan Luar Bandar kepada Kementerian Pelajaran. Jika sebelum ini kedudukan ITM adalah sebagai salah satu institusi pendidikan MARA yang bernaung di bawah Kementerian Pembangunan Negara dan Luar Bandar tetapi kini telah berubah. Ahli Parlimen sebulat suara berpendapat adalah menjadi satu kesilapan untuk meletakkan ITM di bawah Kementerian Pembangunan Negara dan Luar Bandar memandangkan status ITM sebagai sebuah institusi pendidikan yang memerlukan satu pengawasan rapi dan persekitaran yang sihat bagi menggalakkan pelajar menimba ilmu pengetahuan. ${ }^{62}$ Ternyata kemampuan MARA untuk menguruskan sebuah institusi pendidikan tinggi sedikit tercalar ekoran dari insiden yang berlaku.

Seksyen 4 dalam Rang Undang-undang tersebut juga memberi kuasa untuk ITM menyediakan kursus pengajian, mengadakan peperiksaan dan mengambil sebarang tindakan yang sesuai bagi pelajaran dan latihan dalam pelbagai bidang pekerjaan termasuklah bidang sains, teknologi, perniagaan, perindustrian, pengurusan dan pentadbiran. Ia juga boleh menganugerahkan diploma dan sijil kepada sesiapa yang mengikuti kursus pengajiannya di institusi yang diluluskan. ${ }^{63}$ Selain itu, dalam aspek tatatertib pula, satu undangundang telah digubal bagi mengawal tatatertib dalam ITM. Dengan adanya undang-undang ini ketenteraman dalam ITM dapat dikawal oleh undang-undang yang kukuh dan kuat. Ketiadaan undang-undang tersendiri telah mengakibatkan masalah sebegini berlaku. Malah sepanjang tahun akademik 1975 hingga 1976, ITM telah menjadi medan pertelingkahan pelajar. Penuntut ITM mengadakan pelbagai kegiatan yang bukan sahaja mencegah ketenteraman malah menghalang aktiviti pembelajaran berjalan dengan lancar. ${ }^{64}$ Oleh itu, adalah perlu untuk mengadakan satu undang-undang bagi mengawal tindak-tanduk pelajar. Dengan adanya Rang Undang-undang ITM ini, ketenteraman 
dalam ITM dapat dikawal malah pelajar lebih akur dengan peraturan yang ketat. ${ }^{65}$

Menurut Seksyen 10 Rang Undang-undang tersebut, termaktub larangan pelajar daripada melibatkan diri dalam persatuan, parti politik, kesatuan sekerja dan lain-lain pertubuhan. Seksyen ini juga melarang seseorang pelajar atau pertubuhan daripada menyatakan sokongan, simpati atau bangkangan terhadap sesuatu parti politik. Larangan ini bertujuan untuk memusatkan perhatian pelajar pada ilmu pengetahuan dan menghindarkan pelajar daripada menyertai kegiatan yang bertentangan dengan tugas mereka sebagai seorang pelajar. ${ }^{66}$ Dengan tergubalnya Rang Undang-undang ITM dan Undang-undang Tatatertib, secara tidak langsung telah membawa ITM kepada satu lembaran baru dengan bentuk pentadbiran yang lebih tersusun dan cekap. ITM telah menjadi sebuah badan berkanun di bawah Kementerian Pelajaran. Pemindahan ITM ke Kementerian Pelajaran dianggap perlu kerana ia dirancang sebagai institusi pendidikan yang mengambil penuntut dalam kalangan para pelajar sekolah. Sudah tiba masanya ITM bersaing dengan institusi pendidikan yang lain. Berada di bawah Kementerian Pelajaran juga akan membantu ITM mendapatkan maklumat tentang pendidikan dari Kementerian Pelajaran. ${ }^{67}$

Dalam Undang-undang ITM telah termaktub dalam Seksyen 35(2) iaitu Bahagian VII beberapa peruntukan peralihan untuk menentukan bahawa perubahan taraf Institut Teknologi MARA daripada sebuah institusi pendidikan yang dikendalikan oleh Majlis Amanah Rakyat (MARA) kepada sebuah badan berkanun. Ia dinyatakan seperti berikut:

Subject to the provisions of this Act, all powers, rights, privileges, duties, liabilities or obligations which immediately before the appointed date were those of MARA in respect of ITM, or those of ITM, shall, as from the date, devolve on the Universiti (ITM) established by this Act. ${ }^{68}$

Selain itu, segala bentuk aset berupa tanah dan apa jua yang menjadi milik ITM ketika di bawah MARA hendaklah dipindahkan serta-merta di bawah kuasa ITM sendiri berkuatkuasa dari tarikh akta ini diluluskan. Ini bermakna semua harta yang sedang digunakan oleh ITM sekarang termasuk mana-mana tanah atas nama MARA sekarang telah menjadi hak ITM. ${ }^{69}$ Walau bagaimanapun, perkataan MARA yang terletak di hujung nama ITM tidak digugurkan bagi melambangkan asal-usulnya sebagai institut yang ditubuhkan di bawah MARA. ${ }^{70}$ Ekoran daripada demonstrasi yang dijalankan oleh pelajar telah sedikit sebanyak menjejaskan prestasi para pelajar ITM secara keseluruhannya. Ini dapat dilihat melalui keputusan peperiksaan para pelajar bagi tahun 1976. 
Jadual 3: Keputusan Peperiksaan Bagi Jun 1976

\begin{tabular}{|l|c|c|}
\hline Keputusan & Diploma Tinggi & Diploma \\
\hline Lulus & 529 & 36 \\
\hline Lulus selepas mengulang & 44 & 12 \\
\hline Mengulang semua subjek & - & 3 \\
\hline Dalam perhatian & 136 & - \\
\hline Diberhentikan & 92 & - \\
\hline Jumlah & 801 & 51 \\
\hline
\end{tabular}

Sumber: Laporan Tahunan ITM 1976, hlm. 33.

Jadual 4: Keputusan Peperiksaan Bulan Disember 1976

\begin{tabular}{|l|c|c|}
\hline Keputusan & Peringkat Diploma & Diploma Tinggi \\
\hline Lulus & 553 & 13 \\
\hline Lulus selepas mengulang & 63 & 1 \\
\hline Dalam perhatian & 153 & 1 \\
\hline Diberhentikan & 125 & - \\
\hline Jumlah & 894 & 15 \\
\hline
\end{tabular}

Sumber: Laporan Tahunan ITM 1976, hlm. 34.

Melalui jadual di atas, dapat dikenalpasti jumlah pelajar yang lulus, lulus selepas mengulang, dalam perhatian dan diberhentikan. Misalnya, jumlah pelajar yang diberhentikan telah meningkat daripada 92 orang kepada 125 orang. Manakala jumlah pelajar yang dalam perhatian juga meningkat daripada 136 orang kepada 153 orang. Ini menunjukkan bahawa tunjuk perasaan yang berlaku memberi kesan kepada pelajar dan menjadikan ITM itu sendiri sebagai medan pertelingkahan. Tuduh menuduh dan syak wasangka yang berleluasa telah mengganggu proses pembelajaran ilmu dalam kalangan pelajar.

Jelas di sini bahawa langkah-langkah positif yang telah diambil oleh pihak kerajaan melalui ITM ini telah berjaya mengubah tindak tanduk pelajar agar lebih fokus terhadap tanggungjawab mereka sebagai seorang pelajar. ${ }^{71}$ Dengan pengenalan Undang-undang ITM dan Akta Institusi-institusi Pelajaran (tatatertib) 1976, telah berjaya mengawal tindak tanduk pelajar ITM. Aktiviti selain pendidikan dapat dicegah dan para pelajar dapat belajar dalam keadaan yang kondusif. Sebarang bentuk tindakan yang mempengaruhi pelajar juga dapat dibanteras dengan mudah kerana ada akta yang menghalang kegiatan tersebut. Ini secara tidak langsung akan menjamin perkembangan pendidikan ITM itu sendiri. 


\section{Kesimpulan}

Sepertimana MARA, penubuhan ITM juga bukan suatu kelahiran baru. Ia merupakan penjenamaan semula daripada Dewan Latihan RIDA yang dinaiktaraf kepada Maktab MARA dan kemudiannya diberi imej baru dengan nama Institut Teknologi MARA. Peranan MARA dalam menubuhkan institusi ini dicetuskan dalam senario kegelisahan cendekiawan dan ahli politik Bumiputera yang mahukan persaingan ke arah kemakmuran mengambil pendekatan tindakan afirmatif oleh pihak kerajaan. Dalam menyahut cabaran tersebut, MARA dilihat telah berjaya menyediakan suatu lapangan yang melahirkan golongan Bumiputera profesional.

Dalam satu dekad terawal penubuhannya, ITM telah menyediakan pelbagai kursus profesional dengan harapan memberi latihan yang secukupnya kepada golongan Bumiputera untuk memasuki pasaran pekerjaan. Dengan serampang Dasar Ekonomi Baru harapan MARA menjadi lebih mudah bahkan ia menjadi salah satu mekanisme kerajaan dalam memerangi kedaifan daya saing golongan Bumiputera. Walau bagaimanapun dalam keghairahan pihak MARA memperluaskan keupayaan ITM ia ditentang oleh suatu cabaran besar yang akhirnya telah menatijahkan peralihan pentadbiran ITM kepada Kementerian Pelajaran Malaysia. Kegagalan MARA menangani rusuhan para pelajarnya menyebabkan MARA didakwa tidak lagi sesuai untuk mentadbir ITM yang kini sudah menjadi institut pengajian tinggi yang lengkap putaran kematangannya.

\section{Nota}

1 Rujuk Ucapan Timbalan Perdana Menteri semasa bacaan kali kedua "Timbalan Yang di Pertuan Agong (Remuneration Amendment Bill) di Dewan Rakyat pada 3 Jun 1965, Ucapan Tun Hj Abdul Razak bin Hussein 1965, Arkib Negara Malaysia, hlm. 74.

$2 \quad$ RIDA atau Rural Industrial Development Authority ditubuhkan ketika negara belum mencapai kemerdekaan iaitu pada bulan Ogos 1950. D.E.Fiennes,1957, Report on Rural Industrial and Development Authority 1950-1955, Kuala Lumpur:Government Press, hlm. 2.

3 Ahli-ahlinya adalah terdiri daripada: Y.B Encik Mohamed Khir Johari (Pengerusi), Y.B. Encik Abdul Rahman Ya'akub (Timbalan Pengerusi), Y. M. Tunku Abdullah Ibni Tuanku Abdul Rahman (Setiausaha Agong), Y.B. Encik Senu bin Abdul Rahman, Y.B. Tn Hj Mohamed Ghazali bin Hj Jawi, Y.B. Dato' V.T. Sambathan, Y.B. Encik Khaw Kai Boh, Y.B. Tuan Haji Abdul Khalid bin Awang Osman, Y. B. Encik Sulaiman bin Bulon, Y.B. Dato' Nik Ahmad Kamil, Y.B. Encik Hanafiah bin Hussein, Dato' Ismail bin Mohamed Ali, Dato' Abdul Rahman bin Musa, Encik Ma'arof bin Sheikh Ahmad, Y.M. Raja Mohar bin Raja Badiozaman, Y.M. Raja Khalid bin Raja Harun, dan Encik Wan Abdul Hamid bin Dato' Mohd Salleh. 
Rujuk Usul Kongres Ekonomi Bumiputera, Kementerian Pembangunan Negara dan Luar Bandar, hlm. 3.

4 Antara Jawatankuasa Kecil tersebut adalah Jawatankuasa Kecil Latihan, Jawatankuasa Kecil Pembentukan Modal, Jawatankuasa Kecil Perkhidmatan, Jawatankusa Kecil Perusahaan, Jawatankuasa Kecil Perniagaan, Jawatankuasa Kecil Tanah, dan Jawatankuasa Kecil Pemasaran. Rujuk Usul Kongres Ekonomi Bumiputera, Kementerian Pembangunan Negara dan Luar Bandar, hlm. 3.

5 Sebuah Syarikat Permodalan Kebangsaan Berhad didesak agar diperluaskan hak miliknya dan menyemak syarat penubuhannya agar dapat membantu Bumiputera meluaskan hak pemilikan modal. Rujuk Usul Kongres Ekonomi Bumiputera, hlm. 2.

6 Perkhidmatan khas bagi memberi nasihat dan panduan kepada Bumiputera disediakan. Begitu juga kemudahan bagi peniaga untuk berhubung antara sama lain juga disediakan. Rujuk Usul Kongres Ekonomi Bumiputera, hlm. 3.

7 Kerajaan akan menyediakan satu Jabatan Perangkaan untuk membuat penyiasatan bagi kegunaan peniaga-peniaga Bumiputera. Dewan Perniagaan Bumiputera juga akan menubuhkan satu Jabatan Penerangan bagi memberi penerangan kepada peniaga Bumiputera dalam lapangan perniagaan dan perdagangan. Rujuk Usul Kongres Ekonomi Bumiputera, hlm. 3.

$8 \quad$ Kerajaan akan mengadakan kemudahan bagi memperbaiki pemasaran hasil pertanian dan perusahaan Bumiputera. Sebuah lembaga pemasaran pertanian juga akan ditubuhkan bagi tujuan pemasaran. Parliamentary Debates, Dewan Rakyat, Volume II, No.1, 1965, hlm. 310.

9 Rujuk Ucapan Timbalan Perdana Menteri semasa bacaan kali kedua “Timbalan Yang di Pertuan Agong (Remuneration Amendment Bill) di Dewan Rakyat pada 3 Jun 1965,Ucapan Tun Hj Abdul Razak bin Hussein 1965, Arkib Negara Malaysia, hlm. 74. Akta MARA, 1966, Dany Press, hlm. 8-9. Parliamentary Debates, Dewan Rakyat, Volume II, No.12, 1966, hlm. 2196. Laporan Tahunan MARA 1966, hlm. 14-16.

13 Parlimentary Debates, Dewan Rakyat, Volume II, No.12, 1966, hlm. 22002202.

$14 \quad$ Ibid

15 Latar Belakang Majlis Amanah Rakyat, Ibu Pejabat MARA, Kuala Lumpur, 21 Jun 1966, hlm. 3.

16 Encik Mansor bin Othman telah dilahirkan di Kuala Pilah pada 12 Januari 1924. Beliau mendapat pendidikan di Sekolah Melayu Kuala Pilah dan di Sekolah Tuanku Mohammad Kuala Pilah. Pada tahun 1941, beliau telah melanjutkan pelajarannya di Raffles College Singapura tetapi pelajaran beliau terganggu akibat Perang Dunia Kedua. Beliau meneruskan semula pengajian dari tahun 1946 hingga tahun 1948. Beliau menjawat jawatan sebagai seorang guru di Negeri Sembilan dan telah memegang jawatan sebagai Pegawai Pelajaran apabila beliau memeperoleh Ijazah Honours dalam Ilmu Hisab daripada Universiti Malaya, Singapura. Pada tahun 
1954, beliau telah meninggalkan jawatan sebagai guru dan berkhidmat di Syarikat Shell Malaysia Berhad. Jawatan beliau yang terakhir sebelum beliau dipinjamkan oleh Shell kepada MARA ialah sebagai Pegawai Perhubungan Raya. Beliau berkhidmat sebagai Pengarah Bahagian Latihan MARA sehingga 4 April 1969. Rujuk Fail Peribadi En Mansor bin Othman, Bahagian Sumber Manusia MARA. Marina Samad, The MARA Institute of Technology: Yesterday, Today dan Tomorrow, Kuala Lumpur: ITM, 1969, hlm. 40.

$18 \quad$ Kertas kerja Kongres Ekonomi Bumiputera, 5 Januari 1965.

19 Kongres Ekonomi Bumiputera, 7 Jun 1965, hlm 2. Rujuk juga Rokiah Talib, A Second Chance: Life and Mission of Arshad Ayub, Kuala Lumpur: MPH, hlm. 49.

$20 \quad$ Kongres Ekonomi Bumiputera, 7 Jun 1965, hlm. 10. Rokiah Talib, The Second Chance: Life and Mission of Arsyad Ayub, hlm. 4060.

22 Dr. O.G.Pickard, Pengetua Ealing Technical College(U.K) telah dijemput untuk melawat Malaysia dari bulan November ke Disember 1965 untuk melihat akan kemungkinan mengadakan kursus yang bertujuan mendapatkan Diploma yang akan dianugerahkan Diploma Bersekutu. Rujuk 10 Tahun Institut Teknologi MARA dalam Kenangan, hlm. 2. Rujuk juga Kertas kerja konsep cadangan projek pengkisahan sejarah penubuhan dan perkembangan UiTM, 15 Mac 2001, hlm.1. The Straits Times, 13 Februari 1966, hlm. 14.

10 Tahun Institut Teknologi MARA dalam kenangan, hlm. 7. Pada awal penubuhan ITM, ia amat terkenal dengan panggilan akronim MIT. Menurut Tan Sri Arshad Ayub, panggilan MIT itu amat sinonim dengan Massachusetts Institute of Technology and Manchaster Institute of Technology yang merupakan dua buah institusi terkenal di dunia dan beliau sendiri amat meminati institusi tersebut. Ucapan Tan Sri Arshad Ayub sempena Majlis Pengkisahan Sejarah Penubuhan dan Perkembangan UiTM, 15 Mac 2001, hlm. 3.

Hawa Rohani et.al. Documenting A Destiny: History of Universiti Teknologi MARA 1956-2006, 2006, hlm. 74. Rujuk juga Prospektus Institut Teknologi MARA 1968/69, hlm. 5. Rujuk juga Firdaus Ahmad Azzam. ITM Warisan Bangsa, 1989, hlm. 4. Rujuk juga Berita Harian, 4 Mac 1966.

Taklimat kepada Y.B. Datuk Musa Hitam, Menteri Pelajaran Malaysia daripada Pengarah Institut Teknologi MARA Shah Alam, Selangor,15 Januari 1981, hlm. 21.

Kajian Semula Rancangan Malaysia ke-3 1976-1980, Institut Teknologi MARA, hlm. 1.

28 Prospektus Institut Teknologi MARA 1968/69, hlm. 3.

29 Rujuk Berita Harian, 10 Disember 1965.

30 Surat Encik Arshad Ayub kepada Encik Abdul Rahman Hamid selaku Pengarah Bahagian Latihan MARA, 19 Julai 1969 dalam Memorandum MIT Governing Council. Ibid.

32 Ibid. 
33 Rujuk Utusan Malaysia, 15 Januari 1970.

$34 \quad$ Firdaus Ahmad Azzam, ITM Warisan Bangsa, 1989, hlm. 21.

35 Rujuk Berita Harian, 15 Januari 1970.

36 Rujuk Berita Harian, 17 Januari 1970.

37 Rujuk Utusan Malaysia, 9 Februari 1970.

38 Tan Sri Ghazali Shafie telah berkhidmat sebagai Pengerusi Majlis Pentadbir dari 15 Januari 1970 hingga 28 Ogos 1975. Sewaktu beliau mentadbir ITM, beliau telah membentuk dan memperkukuhkan struktur ITM sebagai sebuah Institusi Pengajian Tinggi. Rujuk Hawa Rohany et.al. Documenting A Destiny:History of University Teknologi MARA 1956-2006, hlm. 74. 10 Tahun Institut Teknologi MARA dalam kenangan, hlm. 9.

$40 \quad$ Ibid, hlm. 13.

41 Shaping A Dream From Dewan Latihan RIDA to Universiti Teknologi MARA 1956-1999, hlm. 17.

42 Rokiah Talib, A Second Chance: Life and Mission of Arshad Ayub, hlm. 62-66.

$43 \quad$ Ibid., hlm. 76-77.

$44 \quad$ Rujuk Berita Harian, 17 Januari 1971.

$45 \quad$ Rujuk Berita Harian, 2 Februari 1973.

Rujuk Berita Harian, 2 Februari 1974 dan 23 Februari 1974.

Rujuk Berita Harian, 23 Mei 1974.

Rujuk Minit Mesyuarat Tergempar Majlis Pentadbir ITM, Fail Arkib UiTM, 22 April 1974, jam 11.30 pagi .

Rujuk Minit Mesyuarat Khas Majlis Pentadbir ITM, Fail Arkib UiTM, 18 Mei 1974, jam 9.15 pagi.

Rujuk Utusan Malaysia, 13 Januari 1976.

Pengarah ITM telah mengeluarkan surat pekeliling berkenaan disiplin kepada semua pelajar ITM. Salinan surat ini telah dihantar kepada semua ibu bapa dan penjaga pelajar itu. Surat itu menyatakan bahawa pihak pentadbir ITM akan melakanakan dengan sepenuhnya segala peraturan tatatertib yang telah lama berada di dalam Buku Panduan Pelajar ITM apabila ITM dibuka semula pada 5 Januari 1976. Antara peraturan tersebut ialah kod etika pelajar yang perlu berambut pendek dan berpakaian sopan. Rujuk Penyata Rasmi Parlimen Dewan Negara, 3 Mei 1976, Jilid II, bil.6, hlm. 486. Rujuk Berita Minggu, 11 Januari 1976.

53 Mesyuarat ini merupakan rumusan konferensi tahunan ketua-ketua kajian dan bahagian ITM yang bertemakan " ITM kearah RMK-3", 27 hingga 30 Disember 1975 di Hotel Merlin, Bukit Fraser. Rujuk juga Mingguan Malaysia, 15 Februari 1976. Rujuk Berita Harian, 5 Januari 1976.

$55 \quad$ Rujuk Utusan Malaysia, 14 Februari 1976.

56 Rujuk Berita Harian, 9 Januari 1976. Rujuk juga Penyata Rasmi Parlimen Dewan Rakyat, 15 April 1976, hlm. 1353-1354.

57 Rujuk Berita Harian, 23 Februari 1976.

$58 \quad$ Rujuk Berita Harian, 11 Januari 1976.

$59 \quad$ Rujuk Berita Harian, 5 Januari 1976. 
$60 \quad$ Penyata Rasmi Parlimen, Dewan Negara, 4 Mei 1976, Jilid II, Bil. 7.

61 Rujuk Penyata Rasmi Parlimen Dewan Rakyat, 15 April 1976, hlm. 13451360.

62 Penyata Rasmi Parlimen, Dewan Negara, 4 Mei 1976, Jilid II, bil.7, hlm. 621 dan 631.

63 Ibid, hlm. 622.

64 Penyata Rasmi Parlimen, Dewan Negara, 4 Mei 1976, Jilid II, bil.7, hlm. 630-631.

65 Penyata Rasmi Parlimen, Dewan Rakyat, 15 April 1976, hlm. 1352-1354.

66 Ibid., hlm. 1356.

67 Ibid., hlm. 1230.

68 Rujuk Universiti Teknologi MARA Act 1976, hlm. 36.

69 Minit Mesyuarat Jawatankuasa Pengurusan MARA ke 64 bertarikh 7 April 1976.

$70 \quad$ Ibid., hlm. 35.

71 Ucapan Y.B.Dato' Musa Hitam selaku Menteri Pelajaran Malaysia di Konvokesyen ITM pada 13 dan 14 Oktober 1979, Dewan Besar ITM Shah Alam, hlm. 2. 